\title{
Melanocortin-4 receptor expression in a vago-vagal circuitry involved in postprandial functions
}

\author{
Laurent Gautron ${ }^{1}$, Charlotte Lee ${ }^{1}$, Hisayuki Funahashi ${ }^{2}$, Jeffrey Friedman ${ }^{3}$, Syann Lee ${ }^{1}$, \\ and Joel Elmquist ${ }^{1}$ \\ ${ }^{1}$ Departments of Internal Medicine, Pharmacology, and Psychiatry, Division of Hypothalamic \\ Research, The University of Texas Southwestern Medical Center, 5323 Harry Hines Blvd, Dallas, \\ Texas 75390-9077, Office: +1 214-648-6436, Fax Number: +1 214-648-5612 \\ 2 Department of Anatomy, Showa University School of Medicine, Tokyo, 142-8555 Japan \\ ${ }^{3}$ Laboratory of Molecular Genetics and Howard Hughes Medical Institute, The Rockefeller \\ University, New York, NY 10065, USA
}

\section{Abstract}

Vagal afferents regulate energy balance by providing a link between the brain and postprandial signals originating from the gut. In the current study, we investigated melanocortin-4 receptor (MC4R) expression in the nodose ganglion, where the cell bodies of vagal sensory afferents reside. Using a line of mice expressing Green Fluorescent Protein (GFP) under the control of the MC4R promoter, we found GFP expression in approximately one third of nodose ganglion neurons. Using immunohistochemistry combined with in situ hybridization, we also demonstrated that $\sim 20 \%$ of GFP-positive neurons coexpressed cholecystokinin receptor A. In addition, we found that the GFP is transported to peripheral tissues by both vagal sensory afferents and motor efferents, which allowed us to assess the sites innervated by MC4R-GFP neurons. GFP-positive efferents that co-expressed choline acetyltransferase specifically terminated in the hepatic artery and the myenteric plexus of the stomach and duodenum. In contrast, GFP-positive afferents that did not express cholinergic or sympathetic markers terminated in the submucosal plexus and mucosa of the duodenum. Retrograde tracing experiments confirmed the innervation of the duodenum by GFP-positive neurons located in the nodose ganglion. Our findings support the hypothesis that MC4R signaling in vagal afferents may modulate the activity of fibers sensitive to satiety signals such as cholecystokinin, and that MC4R signaling in vagal efferents may contribute to the control of the liver and gastrointestinal tract.

\section{Keywords}

cholecystokinin; Green fluorescent protein; satiety; vagus nerve

\section{Introduction}

The melanocortin-4 receptor (MC4R) is a major regulator of food intake, body weight and glucose homeostasis (Cone, 2006). For instance, the peripheral and central administration of MC4R agonists suppresses feeding in rats and mice in a dose dependent manner, without producing aversion (Fan et al., 1997; Benoit et al., 2000; Lu et al., 2003; Sutton et al., 2005; Zhang et al., 2005). Likewise, MC4R-induced food suppression is associated with accelerated meal termination (Azzara et al., 2002; Williams et al., 2002). Conversely, mice 
lacking MC4R show hyperphagia, with larger meals and reduced sensitivity to the satiety factor cholecystokinin (CCK) (Huszar et al., 1997; Butler et al., 2001; Fan et al., 2004; Vaughan et al., 2006; Blevins et al., 2009).

We and others have identified multiple brain sites that express MC4R (Mountjoy et al., 1994; Kishi et al., 2003; Liu et al., 2003), a number of which are important in regulating energy balance. Furthermore, genetic models in which MC4R expression can be selectively reactivated in specific neurons have identified the paraventricular hypothalamus and the amygdala as brain sites through which MC4R regulates food intake (Balthasar et al., 2005). However, several other brain sites may contribute to the feeding effects of MC4R, including the nucleus of the solitary tract (NTS) in the brainstem. For example, injections of the MC4R agonist, MTII, into the $4^{\text {th }}$ ventricle (overlying the NTS) decreases food intake, while similar injections of the MC4R antagonist, SHU9119 dose dependently increases food intake (Grill et al., 1998; Williams et al., 2000). Moreover, CCK administration suppresses feeding through the activation of vagal afferents terminating into the NTS, and this effect is prevented by SHU9119 injected into the $4^{\text {th }}$ ventricle (Fan et al., 2004). Finally, Wan and colleagues (2008) also demonstrated that MTII increased the firing frequency of NTS neurons in slice preparations. Importantly, this effect was not mediated by direct postsynaptic action on NTS neurons, but by presynaptic action on the vagal afferents originating from the nodose ganglion (Wan et al., 2008). Using RT-PCR, the same study showed MC4R mRNA expression in the nodose ganglion, where the cell bodies of vagal afferents reside.

Collectively, this suggests that MC4R in vagal afferents may modulate their sensitivity to signals arising from the gut including CCK. Thus, determining MC4R expression in the nodose ganglion will provide a greater understanding of the mechanisms underlying MC4R action. Our current study examines the expression of MC4R in the nodose ganglion using a unique model of MC4R-GFP reporter mice. Additionally, we use immunohistochemistry combined with RNA in situ hybridization to show that MC4R-expressing neurons coexpress CCK receptor A. Lastly, we describe the distribution of GFP-positive vagal fibers and terminals in peripheral tissues involved in regulating energy balance.

\section{Materials and methods}

\section{Animals}

12 MC4R-GFP male mice between 2 and 4 months of age ( $\sim 25 \mathrm{~g}$ ) were housed in a lightcontrolled (12 hours on/12 hours off; lights on at 7 a.m.) and temperature-controlled environment $\left(21.5-22.5^{\circ} \mathrm{C}\right)$. The MC4R-GFP mice express Tau-Sapphire GFP under the control of the MC4R promoter (Liu et al., 2003). The genetic background was an admixture of C57B16/J and CBA. Our group has previously demonstrated that these animals faithfully express GFP in MC4R-expressing neurons (Kishi et al., 2003; Liu et al., 2003). Mice were genotyped as described by Liu and colleagues (2003). The procedures used in this study were approved by the University of Texas Southwestern Medical Center at Dallas Institutional Animal Care and Use Committees.

To label sensory neurons projecting to the gut, a subset of mice received Fluorogold (1\% in saline; Fluorochrome, Inc., Denver, $\mathrm{CO}$ ) in the duodenum ( $\mathrm{n}=3)$. Briefly, mice were anesthetized with Ketamine $\mathrm{HCl} / \mathrm{Xylazine} \mathrm{HCl}(80 / 12 \mathrm{mg} / \mathrm{kg}$, i.p.) and the abdomen was opened longitudinally under aseptic conditions. The stomach and proximal duodenum were gently exposed and Flurogold $(\sim 100 \mu \mathrm{l})$ was injected into the wall of the proximal duodenum using a needle $\left(30 \mathrm{G}^{1 / 2}\right)$ connected to a syringe. A single injection was performed $1 \mathrm{~cm}$ below the pyloric sphincter. After injection, the surface of the duodenum was rinsed with saline to limit contamination of the surrounding tissues. Animals were allowed to 
survive 5 days after surgery. Injection was considered successful when significant fluorescence was seen in freshly isolated duodenum exposed to ultraviolet illumination (see Figure 8).

\section{Tissue preparation}

Mice were deeply anesthetized with chloral hydrate $(500 \mathrm{mg} / \mathrm{kg}$, i.p.), and then perfused transcardially with $0.9 \%$ diethylpyrocarbonate (DEPC)-treated saline followed by $10 \%$ formalin (Sigma). The left nodose ganglion and peripheral organs (including stomach, duodenum, pancreas, liver, spleen, heart, lungs, and adrenals) were removed, post-fixed 2 hours, and submerged in $20 \%$ sucrose overnight at $4^{\circ} \mathrm{C}$. Tissue was embedded in OCT compound (Sakura) and frozen on dry ice. Then, sections were cut at $16 \mu \mathrm{m}$ using a cryostat (1:5 series) collected on Superfrost slides (Fisherbrand) and stored at $-80^{\circ} \mathrm{C}$ until further processing. Whole mounts of the circular muscle of the stomach and duodenum were also sampled and processed for histology immediately after fixation. As a note, our study focused on the left nodose ganglion which is known to innervate the gastrointestinal tract more substantially than the right nodose ganglion does (Berthoud and Neuhuber, 2000).

\section{Antibody Characterization}

The antisera used in the present study are all commercially available and have been tested by different laboratories, and their key features are summarized in Table 1.

1. Rabbit anti-GFP polyclonal antiserum (Invitrogen). The manufacturer has verified that this antibody detects GFP using a Microplate Dilution Assay. Scott and colleagues showed that this antiserum produces no staining in the brain of wildtype mice, but does stain GFP in the brain of transgenic mice that express GFP under the control of the leptin receptor promoter (Scott et al., 2009). The staining that we obtained using this antibody was cytoplasmic and was present in both cell bodies and fibers. Immunoreactivity was absent in nodose ganglia from wild-type mice (not shown). Furthermore, GFP-expressing neurons in the nodose ganglion of GFP reporter mice show endogenous fluorescence (sapphire-GFP/UV filter) that is only enhanced by immunostaining with the antiserum. For instance, the GFP endogenous fluorescence was directly comparable to the immunostaining.

2. Chicken anti-GFP polyclonal antiserum (Aves Laboratories). The manufacturer has previously analyzed the antibody by western blot using transgenic mice expressing the GFP gene product. Western blot analysis produced a single band of $28 \mathrm{kDa}$. Furthermore, Zhao and colleagues (2008) showed that the antiserum produces no staining in the brain of wild-type mice, but did stain brain sections of transgenic mice expressing GFP. In our samples, the antiserum produced directly comparable staining to that obtained with the rabbit antiserum described above.

3. Goat antiserum against Choline acetyltransferase (ChAT) (Chemicon). The antiserum recognizes a single band of approximately 68-70 kDa molecular weight on western blots of mouse brain (Chemicon datasheet), and has been used by others to stain the cholinergic terminals and neurons of the myenteric plexus in rats and guinea pigs (Mawe et al., 1996; Schicho et al., 2001; Miampamba et al., 2002; Kuramoto et al., 2004; 2006). ChAT is commonly used for detecting parasympathetic cholinergic preganglionic terminals as well as a subset of postganglionic myenteric neurons (Mawe et al., 1996; Mann et al., 1999; Schicho et al., 2001; Miampamba et al., 2002; Kuramoto et al., 2004; 2006). In our samples, the antiserum produced a staining pattern identical to previous reports (Mawe et al., 1996; Mann et al., 1999; Schicho et al., 2001; Miampamba et al., 2002; Kuramoto et al., 2004; 2006). 
4. Rabbit polyclonal antiserum against Tyrosine hydroxylase (TH) (Chemicon). The antiserum detects a single band at $62 \mathrm{kDa}$ by western blot (Chemicon datasheet). This antiserum was previously used to stain sympathetic terminals in the mouse lymph nodes and in the mouse myenteric plexus (Carlson et al., 1995; Anderson et al., 2007). In our samples, the antiserum produced intense staining in fibers and varicosities directly comparable to that obtained by others using the same antibody (Anderson et al., 2007) and other antibodies raised against other TH epitopes (Mawe et al., 1996; Phillips et al, 2006; 2007). While TH is commonly used as a marker for sympathetic postganglionic terminals (Mawe et al., 1996; Phillips et al, 2006), TH immunoreactivity is also present in a small subset of nodose ganglion neurons and vagal motor neurons (Katz et al., 1983; Zhuo et al., 1995; Tsukamoto et al., 2005).

5. Rabbit polyclonal antiserum against calcitonin gene-related peptide (CGRP) (Peninsula Laboratories). The antiserum recognizes canine, rat and mouse alphaCGRP as determined by radioimmunoassay (Peninsula datasheet). This antiserum has been reported to label CGRP-positive fibers in mouse oesophageal myenteric ganglion (Kraus et al., 2007), fibers in the lamb intestine (Chiocchetti et al., 2006), and neurons in the mouse trigeminal ganglion (Kosaras et al., 2009). It also detects a single band of $4 \mathrm{kDa}$ on western blots of mouse trigeminal ganglion, and preadsorption with alpha-CGRP eliminated this band (Kosaras et al., 2009). Similarly, preadsorption using CGRP completely prevented the immunostaining in the lamb intestine (Chiocchetti et al., 2006) and the mouse trigeminal ganglion (Kosaras et al., 2009). Spinal afferent terminals in the gastrointestinal tract predominantly contain CGRP (Schutz et al., 2004; Phillips et al., 2007). The staining we obtained with this antibody was in agreement with the known distribution of CGRP in fibers terminating in the myenteric plexus (Schutz et al., 2004; Phillips et al., 2007). CGRP can also be found in a small subset of nodose ganglion neurons (Zhuo et al., 1995).

6. Rabbit polyclonal antiserum against Fluorogold (FG) (Chemicon). Kaufling and colleagues (2009) showed that this antibody stains FG injections sites and retrogradely labeled neurons in the rat brain, but it doesn't stain brain sections of animals without FG injections. The antibody produced a punctate staining in the cytoplasm of retrogradely-labeled neurons in the nodose ganglion. Intraduodenal injections inevitably resulted in misses (i.e. FG delivered into the lumen instead of the wall). Animals with missed injections showed no labeling in the nodose ganglion (not shown).

\section{Immunohistochemistry}

Indirect immunoperoxidase technique-After washing in phosphate-buffered saline (PBS), $\mathrm{pH} 7.4$, nodose ganglion sections were pretreated with $0.3 \%$ hydrogen peroxide in PBS for 15 minutes at room temperature. Sections were incubated overnight in anti-GFP rabbit polyclonal antiserum (see Table 1) in 3\% normal donkey serum (Jackson ImmunoResearch Laboratories Inc., West Grove, PA) with 0.25\% Triton X-100 in PBS (PBT). After washing in PBS, sections were incubated in biotinylated donkey anti-rabbit (Jackson Immunoresearch; cat\#711065152; lot\#81161; 1:1,000), then incubated in a solution of ABC (Vectastain Elite ABC Kit; Vector Laboratories, Burlingame, CA; 1:1,000) dissolved in PBS for 1 hour. After washing in PBS, the sections were incubated in a solution of $0.04 \%$ diaminobenzidine tetrahydrochloride (DAB, Sigma) and $0.01 \%$ hydrogen peroxide (Aldrich). This resulted in a brown cytoplasmic staining. Omission of the primary antiserum eliminated the staining. DAB-labeled sections were air-dried, dehydrated in graded ethanols, 
cleared in xylenes, and coverslipped with Permaslip (Alban Scientific). GFP detection by immunoperoxidase staining was carried out in three MC4R-GFP mice.

Indirect immunofluorescence technique-After washing in PBS, nodose ganglia sections were incubated overnight at room temperature in the anti-GFP rabbit or anti-GFP chicken polyclonal antiserum (Table 1) in 3\% normal donkey serum (Jackson ImmunoResearch Laboratories Inc., West Grove, PA) with 0.25\% Triton X-100 in PBS (PBT). After washing in PBS, sections were incubated in anti-chicken (Invitrogen; cat\#A11039; lot\#488734; 1:1,000) or anti-rabbit (Invitrogen; cat\#A11039; lot\#57542A; 1:1,000) Alexa 488-conjugated secondary antibody for 1 hour at room temperature.

Dual labeling immunohistochemistry-Sections were processed as described above to detect GFP (rabbit or chicken) using a fluorescent secondary antibody. After several washes, sections were incubated overnight with primary antiserum against TH, ChAT, CGRP or Fluorogold (Table 1) in PBT with donkey normal serum. The next day, the tissue was washed and incubated with Alexa 594-conjugated anti-rabbit (Invitrogen; Cat\# A21207; lot\# 404239; 1/1,000) or anti-goat (Invitrogen; Cat\# A11058; lot\# 54258A; 1/1,000) secondary antibodies. Fluorescently-labeled sections were mounted on gelatin-coated slides, air-dried and coverslipped with vectashield mounting medium containing DAPI (Vector laboratories, Burlingame, CA; H-1500). Three MC4R-GFP mice were used for the dual immunohistochemistry experiments.

\section{In situ hybridization combined with immunohistochemistry}

Nodose ganglion sections were fixed in $4 \%$ formaldehyde in DEPC-treated PBS, pH 7.0, for 20 minutes at $4{ }^{\circ} \mathrm{C}$, dehydrated in increasing concentrations of ethanol, cleared in xylenes, rehydrated in decreasing concentrations of ethanol. Sections were incubated in sodium citrate buffer $\left(95-100^{\circ} \mathrm{C}, \mathrm{pH} 6.0\right)$ and microwaved for 10 minutes at $70 \%$ power. Sections were then dehydrated in graded ethanols and air-dried.

The CCKAR probe spans nucleotides 2133-2545 of Genbank accession number NM_009827, and was made from PCR fragments amplified with Taq DNA polymerase (Millipore) from cDNA generated with SuperScript III First-Strand Synthesis System for RT-PCR (Invitrogen, Carlsbad, CA) from total mouse brain RNA (Stratagene). The product was cloned with the TOPO TA Cloning ${ }^{\circledR}$ Kit for Sequencing (Invitrogen). The MC4R antisense probe for MC4R was made exactly as previously described by our group (Balthasar et al., 2005). Antisense and sense ${ }^{35} \mathrm{~S}$ labeled probes were generated with MAXIscript ${ }^{\circledR}$ In Vitro Transcription Kits (Ambion, Austin, TX). The ${ }^{35} \mathrm{~S}$-labeled cRNA probes were diluted to $10^{6} \mathrm{cpm} / \mathrm{ml}$ in a hybridization solution containing $50 \%$ formamide, $10 \mathrm{mM}$ Tris-HCl, $\mathrm{pH}$ 8.0, $5 \mathrm{mg}$ tRNA (Invitrogen), $10 \mathrm{mM}$ dithiothreitol (DTT), 10\% dextran sulfate, $0.3 \mathrm{M} \mathrm{NaCl}, 1 \mathrm{mM}$ EDTA, $\mathrm{pH} 8.0$, and $1 \times$ Denhardt's solution.

Hybridization solution and a coverslip were applied to each slide, and sections were placed at $57^{\circ} \mathrm{C}$ for $12-16$ hours. The next day, sections were washed with $2 \times \mathrm{SSC}$ buffer and incubated in $0.002 \%$ RNase A (Roche Molecular Biochemicals, Indianapolis, IN) with 0.5 $\mathrm{M} \mathrm{NaCl}, 10 \mathrm{mM}$ Tris-HCl, $\mathrm{pH}$ 8.0, and $1 \mathrm{mM}$ EDTA for 30 minutes, followed by a 30 minutes incubation in the same buffer without the RNase. The sections were subsequently incubated in $2 \times \mathrm{SSC}, 0.25 \%$ DTT at $50^{\circ} \mathrm{C}$ for 1 hour, in $0.2 \times \mathrm{SSC}, 0.25 \%$ DTT at $55^{\circ} \mathrm{C}$ for 1 hour, in $0.2 \times \mathrm{SSC}, 0.25 \% \mathrm{DTT}$ at $60^{\circ} \mathrm{C}$ for 1 hour. Afterwards, the sections were rinsed with PBS.

Immunohistochemistry for GFP was performed, as described above, using the immunoperoxidase indirect technique. The DAB staining was optimized by incubating the slides 2 days with diluted rabbit primary antiserum $(1 / 10,0000)$. 
Slides were air-dried and placed in X-ray film cassettes with BMR-2 film (Kodak, Rochester, NY) for 3 days. Slides were then dipped in NTB2 photographic emulsion (Kodak), dried, and stored in desiccated, foil-wrapped boxes at $4^{\circ} \mathrm{C}$ for 6 weeks (MC4R) or 4 weeks (CCKAR). Finally, slides were developed with D-19 developer (Kodak), dehydrated in graded ethanols, cleared in xylenes, and coverslipped with Permaslip (Alban Scientific, St. Louis, MO). Three MC4R-GFP mice were used for dual labeling experiments.

\section{Data analysis and production of digital images}

DAB staining and in situ hybridization materials were viewed using a Zeiss microscope Axioimager Z1 using brightfield optics. Digital images were captured using a digital camera (Axiocam) attached to the microscope and a desktop computer running the Axiovision 3.1 software.

Estimates of double-labeled cells for hybridization and GFP were performed as described in Liu and colleagues (2003). GFP-positive cells were considered double-labeled only if the DAB-stained profile was overlaid by silver grains conforming its shape and at a density at least $2 \times$ above background. Cells with only weak DAB staining or uncertain hybridization signal were excluded. Using this method, we evaluate that GFP colocalized with its own mRNA in $\sim 90 \%$ of the cells (see results). Thus, our results provide relative data which are not meant to be accurate estimates of absolute cell counts. Estimates were done in the left nodose ganglion of 3 different mice. Drawings for double-labeled cells for GFP and CCKAR mRNA were generated using a camera lucida attached to the microscope.

High resolution fluorescent images were generated using stacks of optical sections (between 6 to 10 sections covering a thickness of $\sim 10 \mu \mathrm{m}$ ) obtained with a Zeiss microscope Imager ZI attached to the Apotome system. Images were captured with a digital camera (Axiocam) attached to the microscope and a desktop computer running Axiovision 4.5. To visualize colocalizations, optical sections obtained in 3 different color channels (GFP, CY3 and DAPI filters) were digitally merged using Axiovision 4.5. Counting of GFP-positive neurons was done in DAPI-counterstained sections. Indeed, neuronal nuclei (large and round) were easily distinguished from non-neuronal (elongated and bright) allowing us to count the number of GFP-positive neurons out of 437 neurons (see figure 1) taken from sections $80 \mu \mathrm{m}$ apart from 3 animals.

Qualitative estimates of GFP-positive fibers distribution were performed considering the density of GFP-positive fibers and terminals (density scale: +++ , high $;++$, moderate; + , low; -, absent) and doubly-labeled terminals for TH, CGRP and ChAT.

Photoshop CS2 was used to combine drawings and digital images into plates. The contrast and brightness of images were adjusted. Red-green fluorescence images were converted to magenta-green for the readers who are color blind. Areas of overlap will appear white.

\section{Results}

\section{Specific expression of MC4R in the nodose ganglion}

We assayed GFP expression in the MC4R-GFP reporter mouse and observed a large number of GFP-positive neurons in the left nodose ganglion (Fig.1 B,C). DAB- or fluorescentlylabeled sections resulted in directly comparable results (Fig.1 B,C). Omission of the primary antibody resulted in no specific staining (Fig. 1A). Approximately $30 \%$ of nodose ganglion neurons were positive for GFP (Fig. 1D). MC4R mRNA in situ hybridization followed by GFP immunohistochemistry showed identical distribution patterns for both MC4R mRNA and GFP immunoreactivity in the nodose ganglion (Fig. 1E). In double labeling experiments, $90 \%$ of GFP-profiles also showed silver grains accumulating (Fig. 1F). The 
density of silver grains overlying individual neurons positively correlated with the intensity of GFP immunoreactivity lying beneath (Fig. 1F).

\section{Coexpression of MC4R and CCKAR}

We next carried out in situ hybridization for CCKAR mRNA. As expected, we detected a robust signal for CCKAR mRNA in the left nodose ganglion (Fig. 2A) (Broberger et al., 2001). Using in situ hybridization combined with GFP immunohistochemistry, we detected neurons expressing both GFP and CCKAR in the nodose ganglion (Fig. 2B,b1,b2). A significant proportion of CCKAR-expressing neurons ( $~ 53 \%$ ) expressed GFP (Fig. 2 C), whereas $\sim 20 \%$ of GFP-expressing neurons also expressed CCKAR mRNA (Fig. 2C).

\section{Innervation of the gastroinstestinal tract by MC4R-expressing neurons}

The vagus nerve provides both motor and sensory input to most of the gastrointestinal tract (Berthoud and Neuhuber, 2000) and our current findings and previous data have demonstrated that both vagal sensory and motor neurons express MC4R (Mountjoy et al., 1994; Kishi et al., 2003; Liu et al., 2003). Thus, we assessed GFP immunoreactivity in axons traveling along the vagus nerve as shown in Figure 3. Notably, we identified two types of fibers. The majority of fibers were thin with moderate immunoreactivity, and were distributed throughout the vagal trunk (Fig. 3A,D,G). These fibers did not display choline acetyltransferase (ChAT)-immunoreactivity suggesting that they are sensory afferents (Fig. $4 \mathrm{~B}, \mathrm{C})$. The second type of fibers were thicker with strong immunoreactivity, and were typically seen bundled together (Fig. 3A,D,G). These ticker fibers displayed ChATimmunoreactivity (Fig. 3B, C), and likely originate from the dorsal nucleus of the vagus nerve in which MC4R is abundantly expressed (Mountjoy et al., 1994; Kishi et al., 2003; Liu et al., 2003). GFP-positive fibers were not immunoreactive for tyrosine hydroxylase (TH) (Fig. 3E, F) which identifies a small subset of vagal afferents and efferents, nor for calcitonin gene-related peptide (CGRP) (Fig. 3H, I) which identifies a small subset of vagal afferents.

Since we could clearly see GFP immunoreactivity in fibers traveling through the vagus nerve, we investigated the distribution of GFP-positive fibers and terminals in peripheral tissues. GFP immunoreactivity was abundantly seen in the stomach, portal hilus, and duodenum, but not observed in any other of the tissues examined. In the stomach, GFPpositive fibers were found running through the external muscle layers of the fundus (Fig. 4A,B). GFP-positive fibers in the myenteric plexus formed large conical terminals encircling myenteric neurons (Fig. 4C), which resemble the endings of vagal efferents (Berthoud et al., 1990; Kressel et al., 1994; Phillips et al., 2008). These terminals were ChAT-positive (Fig. $5 B)$.

In peripheral tissues, TH labeling identifies mostly sympathetic postganglionic efferents (Mawe et al., 1996; Phillips et al, 2006) while CGRP is predominantly found in spinal afferents terminals in the gastrointestinal tract (Schutz et al., 2004; Phillips et al., 2007). CGRP- and TH- fibers were frequently seen in the stomach but never colocalized with GFP (Fig. 5D-I), indicating that GFP was not present in spinal afferents or efferents.

The duodenum contained dense innervations of GFP-positive fibers terminating in the myenteric ganglia, submucosal ganglia and mucosa (Fig. 6A,B). Fibers in the myenteric ganglia resembled vagal efferents (Fig. 6C) (Berthoud et al., 1990; Kressel et al., 1994; Phillips et al., 2008). By contrast, GFP fibers in the submucosal ganglia showed complex branching with ornate puncta (Fig. 6D), which are typical of terminals found in the duodenal submucosal ganglia (Kressel et al., 1994). The terminals resembled intraganglionic laminar endings found in the myenteric ganglia, although they are not officially classified as such 
(Kressel et al., 1994; Berthoud et al., 1995). Simple fibers with large varicosities were also found wandering into the villi, which is typical of duodenal chemoreceptors (Fig. 6E) (Berthoud et al., 1995). Of note, a subpopulation of myenteric neurons scattered throughout the circular muscle, the submucosa and mucosa were faintly GFP immunoreactive (Fig 6C inset). GFP-positive terminals in the myenteric ganglia were ChAT-positive (Fig. 7A,B,C), whereas GFP-fibers in the submucosal ganglia and mucosa were always ChAT-negative (D,E), TH-negative (F) and CGRP-negative $(\mathrm{G}, \mathrm{H})$.

Retrograde tracing experiments were conducted to confirm that the fibers observed in the duodenum are sensory afferents from the nodose ganglion. We observed a significant accumulation of Fluorogold in the left nodose ganglion of 3 animals injected in the duodenal wall. Out of 71 retrogradely-labeled neurons, 25 also contained GFP ( 35\%) (Fig. 8A, B).

We did not detect GFP in the portal vein or in the liver parenchyma (Fig. 9B, E). However, GFP immunoreactivity could be observed in parallel arrays of fibers running in the adventitial layers of the common hepatic artery at the level of the hilus (Fig. 9A, C). It is known that the liver receives cholinergic innervation from vagal fibers running along the internal advential layers of the hepatic artery (Amenta et al., 1981), but it is unclear where these fibers terminate since the parenchyma is devoid of significant innervation and parasympathetic ganglia are not found in the liver (Sawchenko and Friedman, 1979; Berthoud, 2004). It is possible, however, that these fibers innervate a small fraction of the paraganglia (Berthoud et al., 1992). Our results are summarized in Table 2.

\section{Discussion}

This study investigated the expression of MC4R in the nodose ganglion using MC4R-GFP reporter mice previously characterized by our group (Kishi et al., 2003; Liu et al., 2003). We found that MC4R-GFP is expressed in a significant proportion of nodose ganglion neurons. Furthermore, many of the GFP-positive neurons in the nodose ganglion co-expressed CCKAR. Lastly, we found that peripheral tissues including the liver, stomach and the duodenum are innervated by GFP-positive vagal afferents and efferents.

\section{Technical considerations}

The current study provides a detailed description of MC4R expression in the nodose ganglion using a unique model of MC4R-GFP reporter mice. Immunohistochemistry for GFP allowed us to easily detect MC4R expression alone or in combination with CCKAR mRNA. As in all studies involving a GFP protein reporter, it is important to confirm the faithful expression of GFP. Here, we have confirmed that the expression of GFP in the nodose ganglion was directly comparable to that of MC4R mRNA and that a majority of GFP-positive profiles also expressed MC4R mRNA. Our findings indicate that the pattern of GFP expression represents endogenous expression of MC4R in the nodose ganglion.

We observed that many CCKAR-expressing neurons also expressed GFP. It is possible that our data may not account for all double-labeled cells because of variability of CCKAR expression. For example, while some neurons had a small number of silver grains, the hybridization signal in other neurons was so dense that it was difficult to visualize GFP staining. Thus, while it is possible that our results underestimate the degree of coexpression, our findings clearly demonstrate co-expression of a significant population of nodose neurons.

Our study also demonstrates that GFP is efficiently transported to axons terminating in peripheral tissues, allowing us to explore sites innervated by MC4R-expressing neurons. Several approaches were used to determine whether GFP-fibers in these tissues were 
afferents or efferents. First, we performed a detailed morphological analysis of the GFPfibers in peripheral tissues, focusing on their resemblance to vagal sensory terminals, which have been previously described in detail by others (Berthoud, 1995; Phillips et al., 2008). Second, immunohistochemical techniques were used to analyze the overlap of GFP-fibers with cholinergic or sympathetic markers. Third, we used retrograde tracing to label nodose ganglion neurons innervating the duodenum. Each of these approaches has inherent limitations. For example, there is currently no unifying marker for vagal afferents, making it difficult to discriminate between vagal afferents and efferents. Also, though CGRP is present in the majority of spinal afferents innervating the stomach and intestines (Green and Dockray, 1988; Phillips et al., 2007), it is not present in all spinal fibers. Consequently, it is possible that some GFP-positive fibers originate from other sensory ganglia (i.e. dorsal root ganglia). Finally, leaking of the tracer during retrograde tracing experiments can generate false positive results. While anterograde tracing methods have been developed to efficiently label either vagal afferents or efferents in rats (Berthoud, 1995; Phillips et al., 2008), those methods remain difficult to perform in mice. Despite these difficulties, the combination of these various approaches provides convincing evidence that GFP is present in a fraction of vagal afferents that innervate the gut, as well as in vagal efferents that innervate the liver and the myenteric plexus of the stomach and intestine.

\section{Functional considerations: MC4R in vagal afferents}

Numerous physiological studies have shown that normal feeding behavior results from the coordinated actions of long-term and short-term metabolic cues. For instance, the administration of leptin and MC4R agonists potentiate the feeding effects of CCK and gastric distension (Barrachina et al., 1997; Emond et al., 1999; Martinez et al., 1999; Morton et al., 2005; Sutton et al., 2005; Huo et al., 2007). Although discrepancies are found in the literature (Vaughan et al., 2006), two studies demonstrated that mice lacking MC4R show reduced sensitivity to CCK (Fan et al., 2004; Blevins et al., 2009). Furthermore, several studies have established that CCKAR expression in vagal afferents is required for the feeding effects of CCK. In the studies presented here, we found that CCKAR-expressing neurons coexpressed MC4R. This observation is consistent with the fact that GFP-fibers were found in the duodenal mucosa where CCK is released during meal ingestion.

Moreover, it has been shown that exogenous CCK exerts its feeding action at the level of the duodenum (Cox, 1998), and that CCKAR-expressing neurons in the nodose ganglion predominantly project to the stomach and duodenum (Burdyga et al., 2004). Hence, it is possible that MC4R signaling in vagal afferents could directly modulate sensitivity to CCK, resulting in increased activation of the brainstem neurons responsible for satiety. However, Williams and colleagues (2000) demonstrated that vagotomized rats (bilateral subdiaphramatic vagotomy) still respond to the anorectic effect of MTII, a MC4R agonist, suggesting that the vagus nerve is not required for the feeding actions of MC4R.

It is possible that MC4R signaling in vagal afferents may be important in these functions rather than food intake. For instance, CCK controls a wide range of postprandial functions including gallbladder contraction, insulin secretion, gastric emptying, and intestinal motility (Moran et al., 2001; Chandra and Liddle, 2007). Furthermore, we found that many MC4Rexpressing neurons do not express CCKAR, instead, many of the GFP-positive terminals in the duodenum resembled intraganglionic laminar endings which could be tension sensors. Also, not all fluorogold-labeled neurons innervating the duodenum demonstrated GFP fluorescence, suggesting that GFP was present only in a specific subset of neurons innervating the gut. Additionally, we did not see terminals resembling intramuscular endings and which are thought to be stretch sensors. Further studies are needed to determine whether or not MC4R is co-expressed with other receptors important in gut functions. 
The cellular localization of MC4R along vagal fibers remains a matter of debate. Although alpha-melanocyte-stimulating hormone $(\alpha-\mathrm{MSH})$ is expressed in peripheral tissues and detectable at low levels in the serum (DeBold et al., 1988; Gavrila et al., 2005), the physiological significance of peripheral $\alpha-\mathrm{MSH}$ in feeding remains unclear. It is possible that MC4R is transported to the terminals of nodose neurons in the nucleus of the solitary tract (NTS). For example, previous electrophysiological findings (Wan et al., 2008) suggest that MC4R is located in presynaptic terminals within the NTS. This is consistent with the abundant innervation of the NTS by $\alpha$-MSH fibers (Zheng et al., 2005). This issue of MC4R cellular localization will remain unclear until MC4R antiserum become available.

\section{Functional considerations: MC4R in vagal efferents}

It is well recognized that MC4R regulate glucose homeostasis. For example, the pharmacological blockade of MC4R signaling in the brain prevents the action of leptin and insulin on glucose uptake and production (Obici et al., 2001; Gutiérrez-Juárez et al., 2004). In contrast, the stimulation of MC4R signaling inhibits insulin release (Fan et al., 2000; Blüher et al., 2004). However, the brain sites that mediate the effects of MC4R on glucose homeostasis remain unknown. Our results indicate that MC4R-expressing neurons in the dorsal nucleus of the vagus nerve directly innervate the hepatic artery. Early work by Shimazu and Fujimoto (1971) suggested that vagal cholinergic transmission to the liver increases glycogen synthesis. Recently, it has been shown that the actions of central insulin on hepatic glucose production depends on the integrity of vagal fibers innervating the liver (Obici et al., 2002; Pocai et al., 2005). Thus, the stimulation of MC4R in the dorsal nucleus of the vagus nerve may alter hepatic function, which could explain the actions of MC4R on glucose homeostasis.

Our findings also show MC4R-expressing vagal efferents that innervate the myenteric plexus. These neurons could control several functions including gut motility and intestinal endocrine secretions. Clearly, more studies are needed to clarify the role of MC4R in vagal efferents.

\section{Conclusion}

Pharmacological agents modulating MC4R signaling are currently being tested to treat metabolic and eating disorders (Foster et al., 2003). However, the neural pathways underlying the potential anti-obesity and anti-diabetic actions of MC4R remain largely unknown. Our data suggest that MC4R signaling is ideally positioned to modulate vagovagal reflexes involved in postprandial functions. MC4R signaling in vagal afferents may modulate sensitivity to signals arising from the gut, including cholecystokinin, while MC4Rexpressing vagal efferents that innervate the liver and myenteric plexus probably influence glucose homeostasis, gut motility and intestinal endocrine secretions. Investigating the role of MC4R signaling in the vagus nerve is truly relevant in the fight against obesity and diabetes.

\section{Supplementary Material}

Refer to Web version on PubMed Central for supplementary material.

\section{Acknowledgments}

We would like to thank Swalpa Udit for her technical assistance and Drs. Carol Elias and Jari Rossi for their advice on histology. This work was funded by DK071320, DK053301, DK081185 (J. K. E.) and the American Diabetes Association 1-07-RA-41 (L.G. and J.K.E.). We would also like to thank the Mouse Metabolic Phenotyping Core at University of Texas Southwestern Medical Center at Dallas (supported by PL1 DK081182). 
Funded by: DK071320, DK53301, DK081185 (J. K. E.) and the American Diabetes Association 1-07-RA-41 (L.G. and J.K.E.).

\section{Literature Cited}

Amenta F, Cavallotti C, Ferrante F, Tonelli F. Cholinergic nerves in the human liver. Histochem J. 1981; 13(3):419-424. [PubMed: 7251394]

Anderson G, Noorian AR, Taylor G, Anitha M, Bernhard D, Srinivasan S, Greene JG. Loss of enteric dopaminergic neurons and associated changes in colon motility in an MPTP mouse model of Parkinson's disease. Exp Neurol. 2007; 207(1):4-12. [PubMed: 17586496]

Azzara AV, Sokolnicki JP, Schwartz GJ. Central melanocortin receptor agonist reduces spontaneous and scheduled meal size but does not augment duodenal preload-induced feeding inhibition. Physiol Behav. 2002; 77(2-3):411-416. [PubMed: 12419417]

Balthasar N, Dalgaard LT, Lee CE, Yu J, Funahashi H, Williams T, Ferreira M, Tang V, McGovern RA, Kenny CD, Christiansen LM, Edelstein E, Choi B, Boss O, Aschkenasi C, Zhang CY, Mountjoy K, Kishi T, Elmquist JK, Lowell BB. Divergence of melanocortin pathways in the control of food intake and energy expenditure. Cell. 2005; 123(3):493-505. [PubMed: 16269339]

Barrachina MD, Martínez V, Wang L, Wei JY, Taché Y. Synergistic interaction between leptin and cholecystokinin to reduce short-term food intake in lean mice. Proc Natl Acad Sci U S A. 1997; 94(19):10455-10460. [PubMed: 9294232]

Benoit SC, Schwartz MW, Lachey JL, Hagan MM, Rushing PA, Blake KA, Yagaloff KA, Kurylko G, Franco L, Danhoo W, Seeley RJ. A novel selective melanocortin-4 receptor agonist reduces food intake in rats and mice without producing aversive consequences. J Neurosci. 2000; 20(9):34423448. [PubMed: 10777807]

Berthoud HR, Jedrzejewska A, Powley TL. Simultaneous labeling of vagal innervation of the gut and afferent projections from the visceral forebrain with dil injected into the dorsal vagal complex in the rat. J Comp Neurol. 1990; 301(1):65-79. [PubMed: 1706359]

Berthoud HR, Kressel M, Neuhuber WL. An anterograde tracing study of the vagal innervation of rat liver, portal vein and biliary system. Anat Embryol (Berl). 1992; 186(5):431-442. [PubMed: 1280009]

Berthoud HR, Kressel M, Raybould HE, Neuhuber WL. Vagal sensors in the rat duodenal mucosa: distribution and structure as revealed by in vivo DiI-tracing. Anat Embryol. 1995; 191(3):203-212. [PubMed: 7771683]

Berthoud HR, Neuhuber WL. Functional and chemical anatomy of the afferent vagal system. Auton Neurosci. 2000; 85(1-3):1-17. [PubMed: 11189015]

Berthoud HR. Anatomy and function of sensory hepatic nerves. Anat Rec A Discov Mol Cell Evol Biol. 2004; 280(1):827-835. [PubMed: 15382018]

Blevins JE, Morton GJ, Williams DL, Caldwell DW, Bastian LS, Wisse BE, Schwartz MW, Baskin DG. Forebrain melanocortin signaling enhances the hindbrain satiety response to CCK-8. Am J Physiol Regul Integr Comp Physiol. 2009; 296(3):R476-484. [PubMed: 19109369]

Blüher S, Ziotopoulou M, Bullen JW Jr, Moschos SJ, Ungsunan L, Kokkotou E, Maratos-Flier E, Mantzoros CS. Responsiveness to peripherally administered melanocortins in lean and obese mice. Diabetes. 2004; 53(1):82-90. [PubMed: 14693701]

Broberger C, Holmberg K, Shi TJ, Dockray G, Hökfelt T. Expression and regulation of cholecystokinin and cholecystokinin receptors in rat nodose and dorsal root ganglia. Brain Res. 2001; 903(1-2):128-140. [PubMed: 11382396]

Burdyga G, Lal S, Varro A, Dimaline R, Thompson DG, Dockray GJ. Expression of cannabinoid CB1 receptors by vagal afferent neurons is inhibited by cholecystokinin. J Neurosci. 2004; 24(11): 2708-2715. [PubMed: 15028763]

Butler AA, Marks DL, Fan W, Kuhn CM, Bartolome M, Cone RD. Melanocortin-4 receptor is required for acute homeostatic responses to increased dietary fat. Nat Neurosci. 2001; 4(6):605611. [PubMed: 11369941]

Carlson SL, Albers KM, Beiting DJ, Parish M, Conner JM, Davis BM. NGF modulates sympathetic innervation of lymphoid tissues. J Neurosci. 1995; 15(9):5892-5899. [PubMed: 7666174] 
Chandra R, Liddle RA. Cholecystokinin. Curr Opin Endocrinol Diabetes Obes. 2007; 14(1):63-67. [PubMed: 17940422]

Chiocchetti R, Grandis A, Bombardi C, Lucchi ML, Dal Lago DT, Bortolami R, Furness JB. Extrinsic and intrinsic sources of calcitonin gene-related peptide immunoreactivity in the lamb ileum: a morphometric and neurochemical investigation. Cell Tissue Res. 2006; 323(2):183-196. [PubMed: 16228232]

Cone RD. Studies on the physiological functions of the melanocortin system. Endocr Rev. 2006; 27(7):736-749. [PubMed: 17077189]

Cox JE. Cholecystokinin satiety involves CCKA receptors perfused by the superior pancreaticoduodenal artery. Am J Physiol. 1998; 274(5 Pt 2):R1390-1396. [PubMed: 9612407]

DeBold CR, Nicholson WE, Orth DN. Immunoreactive proopiomelanocortin (POMC) peptides and POMC-like messenger ribonucleic acid are present in many rat nonpituitary tissues. Endocrinology. 1988; 122(6):2648-2657. [PubMed: 2836169]

Emond M, Schwartz GJ, Ladenheim EE, Moran TH. Central leptin modulates behavioral and neural responsivity to CCK. Am J Physiol. 1999; 276(5 Pt 2):R1545-1549. [PubMed: 10233050]

Fan W, Boston BA, Kesterson RA, Hruby VJ, Cone RD. Role of melanocortinergic neurons in feeding and the agouti obesity syndrome. Nature. 1997; 385(6612):165-168. [PubMed: 8990120]

Fan W, Dinulescu DM, Butler AA, Zhou J, Marks DL, Cone RD. The central melanocortin system can directly regulate serum insulin levels. Endocrinology. 2000; 141(9):3072-3079. [PubMed: 10965876]

Fan W, Ellacott KL, Halatchev IG, Takahashi K, Yu P, Cone RD. Cholecystokinin-mediated suppression of feeding involves the brainstem melanocortin system. Nat Neurosci. 2004; 7(4): 335-336. [PubMed: 15034587]

Foster AC, Joppa M, Markison S, Gogas KR, Fleck BA, Murphy BJ, Wolff M, Cismowski MJ, Ling N, Goodfellow VS, Chen C, Saunders J, Conlon PJ. Body weight regulation by selective MC4 receptor agonists and antagonists. Ann N Y Acad Sci. 2003; 994:103-110. [PubMed: 12851304]

Gavrila A, Chan JL, Miller LC, Heist K, Yiannakouris N, Mantzoros CS. Circulating melaninconcentrating hormone, agouti-related protein, and alpha-melanocyte-stimulating hormone levels in relation to body composition: alterations in response to food deprivation and recombinant human leptin administration. J Clin Endocrinol Metab. 2005; 90(2):1047-1054. [PubMed: 15546902]

Green T, Dockray GJ. Characterization of the peptidergic afferent innervation of the stomach in the rat, mouse and guinea-pig. Neuroscience. 1988; 25(1):181-193. [PubMed: 2455875]

Grill HJ, Ginsberg AB, Seeley RJ, Kaplan JM. Brainstem application of melanocortin receptor ligands produces long-lasting effects on feeding and body weight. J Neurosci. 1998; 18(23):10128-10135. [PubMed: 9822766]

Gutiérrez-Juárez R, Obici S, Rossetti L. Melanocortin-independent effects of leptin on hepatic glucose fluxes. J Biol Chem. 2004; 279(48):49704-49715. [PubMed: 15364916]

Huo L, Maeng L, Bjørbaek C, Grill HJ. Leptin and the control of food intake: neurons in the nucleus of the solitary tract are activated by both gastric distension and leptin. Endocrinology. 2007; 148(5):2189-2197. [PubMed: 17317774]

Huszar D, Lynch CA, Fairchild-Huntress V, Dunmore JH, Fang Q, Berkemeier LR, Gu W, Kesterson RA, Boston BA, Cone RD, Smith FJ, Campfield LA, Burn P, Lee F. Targeted disruption of the melanocortin-4 receptor results in obesity in mice. Cell. 1997; 88(1):131-141. [PubMed: 9019399]

Katz DM, Markey KA, Goldstein M, Black IB. Expression of catecholaminergic characteristics by primary sensory neurons in the normal adult rat in vivo. Proc Natl Acad Sci U S A. 1983; 80(11): 3526-3530. [PubMed: 6134285]

Kaufling J, Veinante P, Pawlowski SA, Freund-Mercier MJ, Barrot M. Afferents to the GABAergic tail of the ventral tegmental area in the rat. J Comp Neurol. 2009; 513(6):597-621. [PubMed: 19235223]

Kelly AB, Watts AG. Mediation of dehydration-induced peptidergic gene expression in the rat lateral hypothalamic area by forebrain afferent projections. J Comp Neurol. 1996; 370(2):231-246. [PubMed: 8808732] 
Kishi T, Aschkenasi CJ, Lee CE, Mountjoy KG, Saper CB, Elmquist JK. Expression of melanocortin 4 receptor mRNA in the central nervous system of the rat. J Comp Neurol. 2003; 457(3):213-235. [PubMed: 12541307]

Kosaras B, Jakubowski M, Kainz V, Burstein R. Sensory innervation of the calvarial bones of the mouse. J Comp Neurol. 2009; 515(3):331-348. [PubMed: 19425099]

Kraus T, Neuhuber WL, Raab M. Distribution of vesicular glutamate transporter 1 (VGLUT1) in the mouse esophagus. Cell Tissue Res. 2007; 329:205-219. [PubMed: 17508221]

Kressel M, Berthoud HR, Neuhuber WL. Vagal innervation of the rat pylorus: an anterograde tracing study using carbocyanine dyes and laser scanning confocal microscopy. Cell Tissue Res. 1994; 275(1):109-123. [PubMed: 7509721]

Kuramoto H, Oomori Y, Murabayashi H, Kadowaki M, Karaki S, Kuwahara A. Localization of neurokinin 1 receptor (NK1R) immunoreactivity in rat esophagus. J Comp Neurol. 2004; 478(1): 11-21. [PubMed: 15334646]

Kuramoto H, Kadowaki M, Yamamoto T, Kuwano R. Calbindin is predominantly expressed in nitrergic neurons in rat esophagus. Neurosci Lett. 2006; 401(1-2):174-147. [PubMed: 16600497]

Liu H, Kishi T, Roseberry AG, Cai X, Lee CE, Montez JM, Friedman JM, Elmquist JK. Transgenic mice expressing green fluorescent protein under the control of the melanocortin-4 receptor promoter. J Neurosci. 2003; 23(18):7143-7154. [PubMed: 12904474]

Lu XY, Barsh GS, Akil H, Watson SJ. Interaction between alpha-melanocyte-stimulating hormone and corticotropin-releasing hormone in the regulation of feeding and hypothalamo-pituitary-adrenal responses. J Neurosci. 2003; 23(21):7863-7872. [PubMed: 12944516]

Mawe GM, Talmage EK, Lee KP, Parsons RL. Expression of choline acetyltransferase immunoreactivity in guinea pig cardiac ganglia. Cell Tissue Res. 1996; 285(2):281-6. [PubMed: 8766164]

Martínez V, Barrachina MD, Wang L, Taché Y. Intracerebroventricular leptin inhibits gastric emptying of a solid nutrient meal in rats. Neuroreport. 1999; 10(15):3217-21. [PubMed: 10574563]

Miampamba M, Maillot C, Million M, Taché Y. Peripheral CRF activates myenteric neurons in the proximal colon through CRF(1) receptor in conscious rats. Am J Physiol Gastrointest Liver Physiol. 2002; 282(5):G857-865. [PubMed: 11960782]

Moran TH, Ladenheim EE, Schwartz GJ. Within-meal gut feedback signaling. Int J Obes Relat Metab Disord. 2001; 25 5:S39-41. [PubMed: 11840213]

Morton GJ, Blevins JE, Williams DL, Niswender KD, Gelling RW, Rhodes CJ, Baskin DG, Schwartz MW. Leptin action in the forebrain regulates the hindbrain response to satiety signals. J Clin Invest. 2005; 115(3):703-710. [PubMed: 15711637]

Mountjoy KG, Mortrud MT, Low MJ, Simerly RB, Cone RD. Localization of the melanocortin-4 receptor (MC4-R) in neuroendocrine and autonomic control circuits in the brain. Mol Endocrinol. 1994; 8(10):1298-1308. [PubMed: 7854347]

Obici S, Feng Z, Tan J, Liu L, Karkanias G, Rossetti L. Central melanocortin receptors regulate insulin action. J Clin Invest. 2001; 108(7):1079-1085. [PubMed: 11581309]

Obici S, Zhang BB, Karkanias G, Rossetti L. Hypothalamic insulin signaling is required for inhibition of glucose production. Nat Med. 2002; 8(12):1376-1382. [PubMed: 12426561]

Phillips RJ, Rhodes BS, Powley TL. Effects of age on sympathetic innervation of the myenteric plexus and gastrointestinal smooth muscle of Fischer 344 rats. Anat Embryol (Berl). 2006; 211(6):673683. [PubMed: 17024301]

Phillips RJ, Pairitz JC, Powley TL. Age-related neuronal loss in the submucosal plexus of the colon of Fischer 344 rats. Neurobiol Aging. 2007; 28(7):1124-1137. [PubMed: 16793176]

Phillips RJ, Walter GC, Wilder SL, Baronowsky EA, Powley TL. Alpha-synuclein-immunopositive myenteric neurons and vagal preganglionic terminals: Autonomic pathway implicated in Parkinson's disease? Neuroscience. 2008; 153(3):733-750. [PubMed: 18407422]

Pocai A, Obici S, Schwartz GJ, Rossetti L. A brain-liver circuit regulates glucose homeostasis. Cell Metab. 2005; 1(1):53-61. [PubMed: 16054044]

Sawchenko PE, Friedman MI. Sensory functions of the liver-a review. Am J Physiol. 1979; 236(1):R5-20. [PubMed: 373465] 
Schicho R, Schemann M, Holzer P, Lippe IT. Mucosal acid challenge activates nitrergic neurons in myenteric plexus of rat stomach. Am J Physiol Gastrointest Liver Physiol. 2001; 281(5):G13161321. [PubMed: 11668041]

Schütz B, Mauer D, Salmon AM, Changeux JP, Zimmer A. Analysis of the cellular expression pattern of beta-CGRP in alpha-CGRP-deficient mice. J Comp Neurol. 2004; 476(1):32-43. [PubMed: 15236465]

Scott MM, Lachey JL, Sternson SM, Lee CE, Elias CF, Friedman JM, Elmquist JK. Leptin targets in the mouse brain. J Comp Neurol. 2009; 514(5):518-532. [PubMed: 19350671]

Shimazu T, Fujimoto T. Regulation of glycogen metabolism in liver by the autonomic nervous system. IV. Neural control of glycogen biosynthesis. Biochim Biophys Acta. 1971; 252(1):18-27. [PubMed: 5141822]

Sutton GM, Duos B, Patterson LM, Berthoud HR. Melanocortinergic modulation of cholecystokinininduced suppression of feeding through extracellular signal-regulated kinase signaling in rat solitary nucleus. Endocrinology. 2005; 146(9):3739-3747. [PubMed: 15961554]

Tsukamoto K, Hayakawa T, Maeda S, Tanaka K, Seki M, Yamamura T. Projections to the alimentary canal from the dopaminergic neurons in the dorsal motor nucleus of the vagus of the rat. Auton Neurosci. 2005; 123(1-2):12-18. [PubMed: 16213798]

Vaughan CH, Haskell-Luevano C, Andreasen A, Rowland NE. Effects of oral preload, CCK or bombesin administration on short term food intake of melanocortin 4-receptor knockout (MC4RKO) mice. Peptides. 2006; 27(12):3226-3233. [PubMed: 16963158]

Wan S, Browning KN, Coleman FH, Sutton G, Zheng H, Butler A, Berthoud HR, Travagli RA. Presynaptic melanocortin-4 receptors on vagal afferent fibers modulate the excitability of rat nucleus tractus solitarius neurons. J Neurosci. 2008; 28(19):4957-4966. [PubMed: 18463249]

Williams DL, Kaplan JM, Grill HJ. The role of the dorsal vagal complex and the vagus nerve in feeding effects of melanocortin-3/4 receptor stimulation. Endocrinology. 2000; 141(4):1332-1327. [PubMed: 10746636]

Williams DL, Grill HJ, Weiss SM, Baird JP, Kaplan JM. Behavioral processes underlying the intake suppressive effects of melanocortin 3/4 receptor activation in the rat. Psychopharmacology. 2002; 161(1):47-53. [PubMed: 11967630]

Zhang Y, Kilroy GE, Henagan TM, Prpic-Uhing V, Richards WG, Bannon AW, Mynatt RL, Gettys TW. Targeted deletion of melanocortin receptor subtypes 3 and 4, but not CART, alters nutrient partitioning and compromises behavioral and metabolic responses to leptin. FASEB J. 2005; 19(11):1482-1491. [PubMed: 16126916]

Zhao Y, Flandin P, Long JE, Cuesta MD, Westphal H, Rubenstein JL. Distinct molecular pathways for development of telencephalic interneuron subtypes revealed through analysis of Lhx6 mutants. J Comp Neurol. 2008; 510(1):79-99. [PubMed: 18613121]

Zheng H, Patterson LM, Phifer CB, Berthoud HR. Brain stem melanocortinergic modulation of meal size and identification of hypothalamic POMC projections. Am J Physiol. 2005; 289(1):R247-258.

Zhuo H, Lewin AC, Phillips ET, Sinclair CM, Helke CJ. Inhibition of axoplasmic transport in the rat vagus nerve alters the numbers of neuropeptide and tyrosine hydroxylase messenger RNAcontaining and immunoreactive visceral afferent neurons of the nodose ganglion. Neuroscience. 1995; 66(1):175-187. [PubMed: 7543661] 


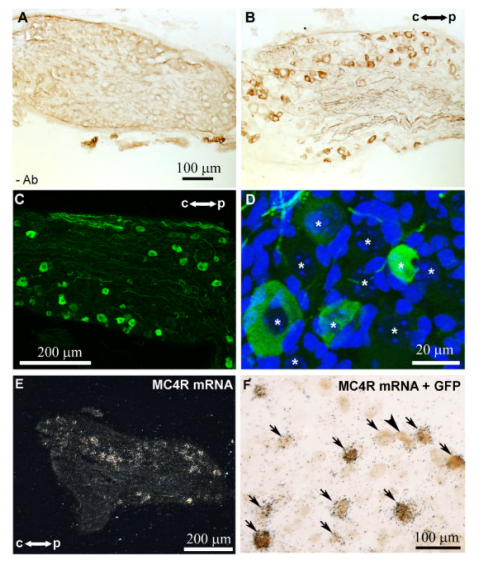

Figure 1.

Immunohistochemical labeling of GFP-positive neurons in the left nodose ganglion. Many GFP-positive neuronal somas and fibers were observed in DAB-labeled (brightfield) (B) and fluorescently-labeled sections (epifluorescence and Apotome) (C). Omission of the primary antibody resulted only in residual background staining (A). Higher magnification of DAPIcounterstained sections reveals neurons (large cellular nuclei marked by asterisks), a number of which show GFP immunoreactivity (D). Note that GFP-positive neurons vary in size. Coexpression of MC4R mRNA and GFP in the left nodose ganglion (E,F). Neurons with clusters of silver grains are visible throughout the ganglion (darkfield) (E). GFP-positive neurons (stained in brown) are overlaid by black silver grains which indicate MC4R mRNA expression (brightfield) (F). Black arrows show examples of colocalization. The black arrowhead shows one example of a GFP-positive profile devoid of hybridization signal. The doubled-headed arrows indicate the central (c) versus the peripheral (p) tip of the ganglion. 

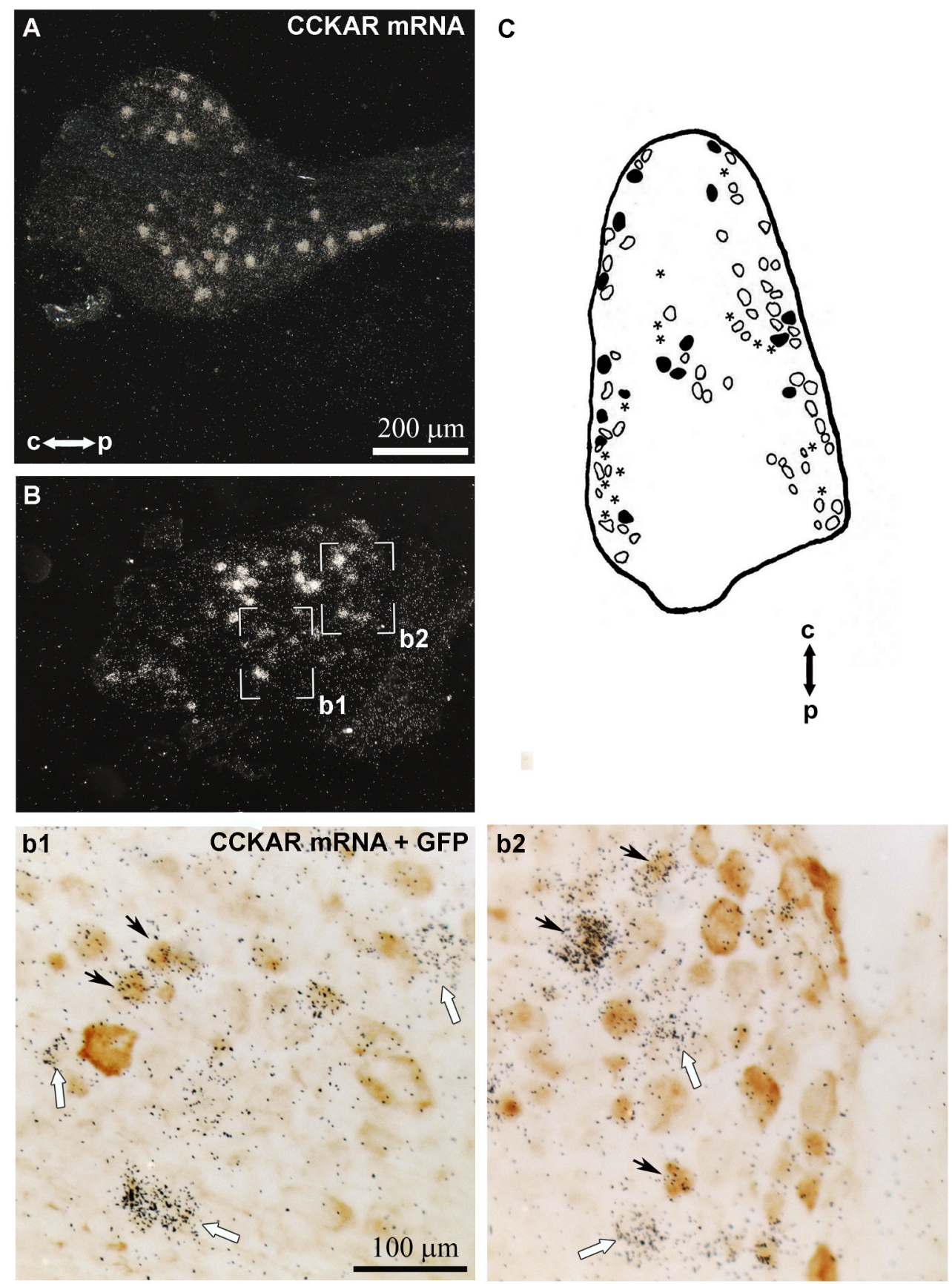

Figure 2.

Coexpression of CCKAR mRNA and GFP in the left nodose ganglion. Robust hybridization signal for CCKAR mRNA is visible in the nodose ganglion (darkfield) (A, B). The boxed areas in B (darkfied) are magnified in b1 and b2 (brightfield). Many GFP-positive neurons (stained in brown) are overlaid by black silver grains which indicate CCKAR mRNA expression (b1, b2). Black arrows show example of double-labeled neurons whereas white arrows show neurons with only CCKAR signal. Drawing showing the distribution of neurons positive only for GFP (open profiles), only for CCKAR (asterisks) or doublelabeled (black profiles) in one representative nodose ganglion (C). Scale bar in A applies through B. The same scale bar applies to b1 and b2. 

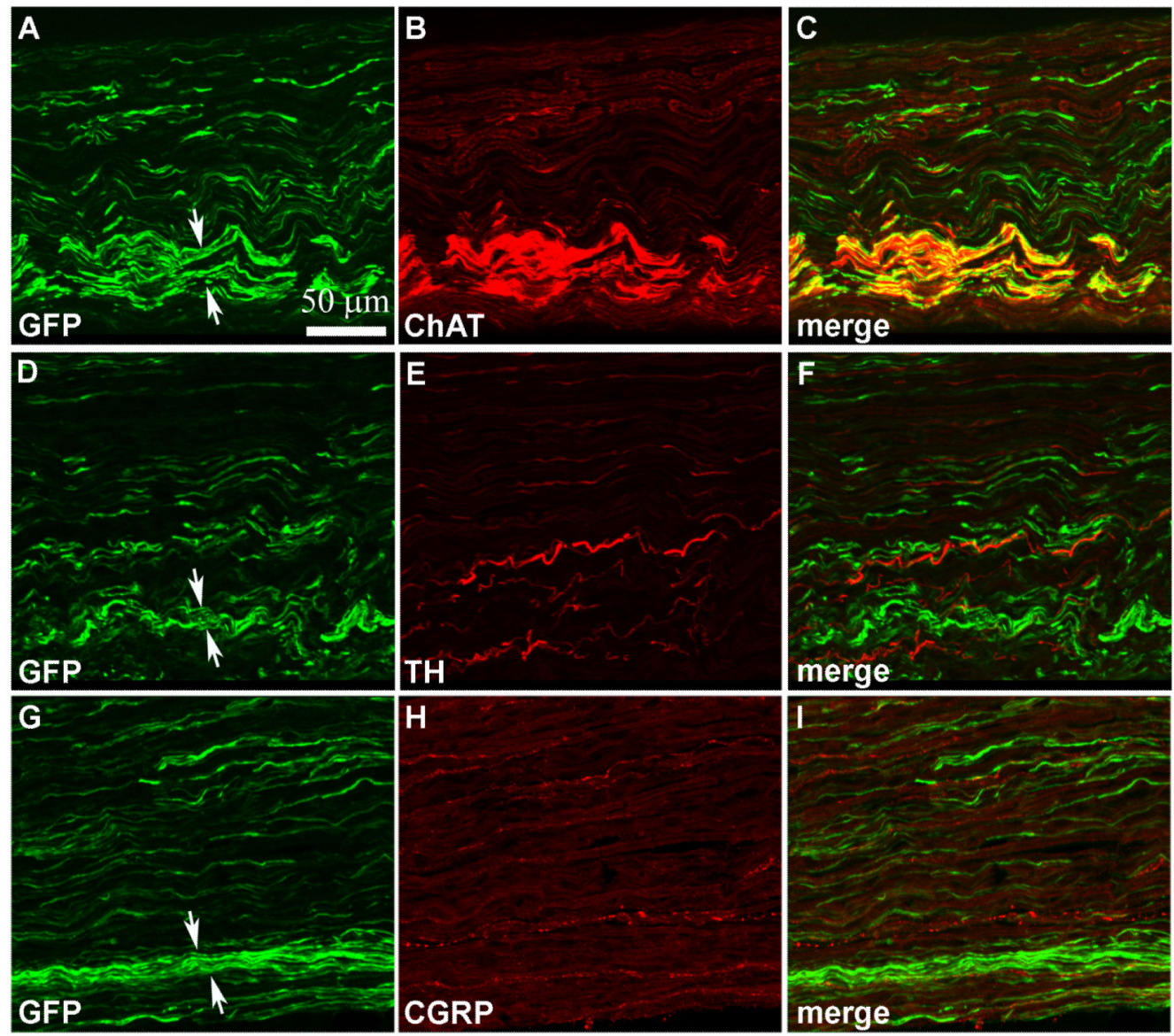

H

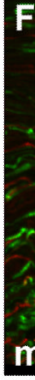

Figure 3.

Immunohistochemical labeling of GFP-positive fibers in the left cervical vagus nerve (epifluorescence and Apotome). GFP-positive fibers are seen coursing the vagal trunk (A, D, $\mathrm{G})$. In the same section, we found ChAT labeling in a subset of vagal fibers corresponding to motor efferent fibers (B). Some GFP-positive fibers (mostly of large diameter; white arrows) colocalized with ChAT (C). TH labeling is observed in a subset of fibers (E), but none of them colocalized with GFP (F). CGRP labeling is also observed $(\mathrm{H})$ but doesn't colocalize with GFP (I). A magenta-green version is provided in supplementary figure 1 . Scale bar in A applies through I. Abbreviations: CGRP, calcitonin gene-related peptide; ChAT, choline acetyltransferase; TH, tyrosine hydroxylase. 

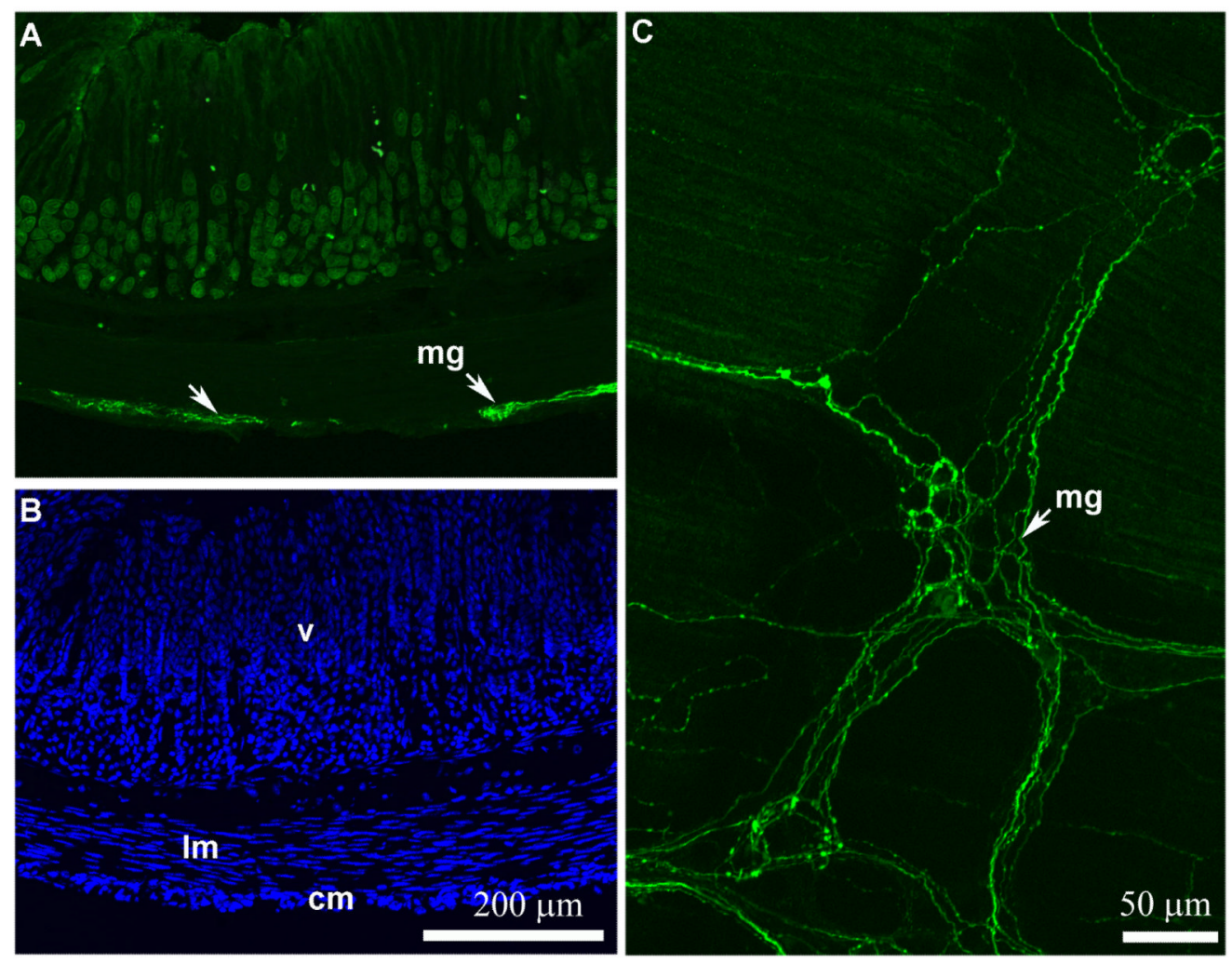

$50 \mu \mathrm{m}$

Figure 4.

Optical sections reconstruction (epifluorescence and Apotome) of GFP-positive fibers in the stomach (A). The histological structure of the stomach is revealed by DAPI staining of the same section (B). The white arrows show GFP-positive fibers running through the external muscle layers. Some bright autofluorescent debris are seen in the villi. Representative GFPpositive endings are shown magnified in a myenteric plexus (whole mount) (C). Note how the GFP-positive terminals resemble vagal efferents terminals. Scale bar in A applies to B. Abbreviations: cm, circular muscles; lm, longitudinal muscles; mg, myenteric ganglion; $\mathrm{v}$, villi. 


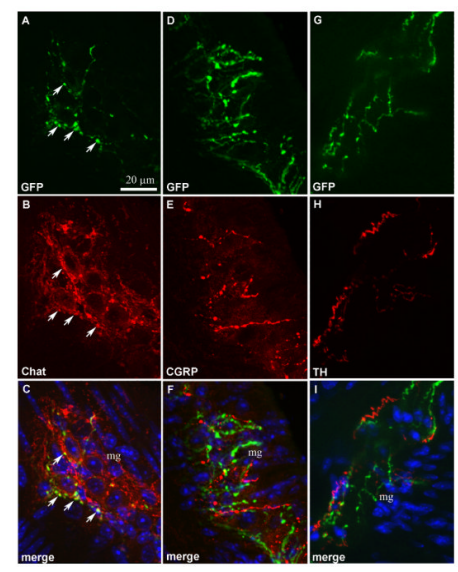

Figure 5.

Double immunolabeling for GFP and ChAT (A, B, C) or CGRP (D,E,F) or TH (G, H, I) in the stomach (epifluorescence and Apotome). GFP-positive endings in myenteric ganglion are shown in A and D. ChAT stains cholinergic terminals in the myenteric plexus (B) and colocalizes with many GFP-positive terminals (C). Numerous CGRP- and TH-positive fibers are seen in myenteric ganglia but do not colocalize with GFP (E,F,H,I). A magentagreen version is provided in supplementary figure 2. Scale bar in A applies through I. Abbreviations: CGRP, calcitonin gene-related peptide; ChAT, choline acetyltransferase; TH, tyrosine hydroxylase $\mathrm{mg}$, myenteric ganglion. 


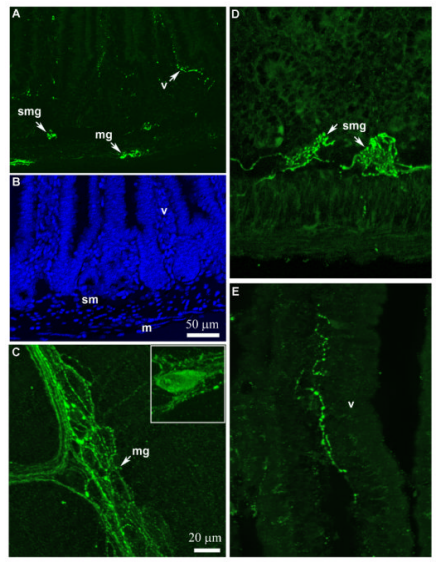

\section{Figure 6.}

Optical sections reconstruction (epifluorescence and Apotome) of GFP-positive fibers in the proximal duodemun (A). The histological structure of the duodenum is revealed by DAPI staining of the same section (B). The white arrows show GFP-positive fibers running through the external muscle layers, ending in myenteric ganglia, and traveling toward the villi (white arrows). GFP-positive endings in the myenteric ganglia typically resembled vagal efferents $(C)$ (whole mount) and occasionally in myenteric neurons (inset), whereas GFP endings in the submucosal ganglion typically resembled specialized sensory terminals known as intraganglionic laminar endings (D). Fibers with large varicosities are seen in the villi (E). Scale bar in A applies to B. Scale bar in C applies through E. Abbreviations: m, muscle layer; mg, myenteric ganglion; sm, submucosal space; smg, submucosal ganglion; v, villi. 


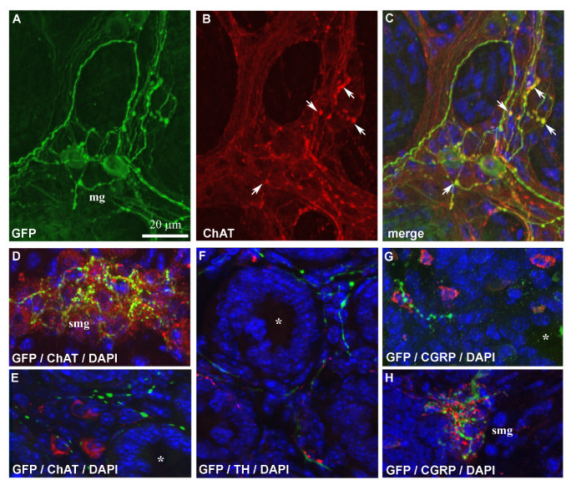

Figure 7.

Double immunolabeling for GFP and ChAT (A-E) or TH $(\mathrm{F})$ or CGRP $(\mathrm{G}, \mathrm{H})$ in the proximal duodenum (epifluorescence and Apotome). GFP-positive endings in a myenteric plexus is shown in A (whole mount). They show typical conical shaped terminals surrounding myenteric neurons which are ChAT-positive (B,C) (white arrows). Some ChAT-negative GFP fibers may be afferents traveling in the muscle toward the submucosa and mucosa. By contrast, GFP-positive fibers in the submucosal myenteric ganglia and villi did not colocalized with ChAT (D,E). GFP-positive fibers never colocalized with TH (F) or CGRP $(\mathrm{G}, \mathrm{H})$. Asterisks indicate the position of the duodenal lumen on transversal sections of the mucosa $(\mathrm{E}, \mathrm{F}, \mathrm{G})$. A magenta-green version is provided in supplementary figure 3 . Scale bar in A applies through H. Abbreviations: CGRP, calcitonin gene-related peptide; ChAT, choline acetyltransferase; TH, tyrosine hydroxylase; smg, submucosal ganglion; mg, myenteric ganglion. 


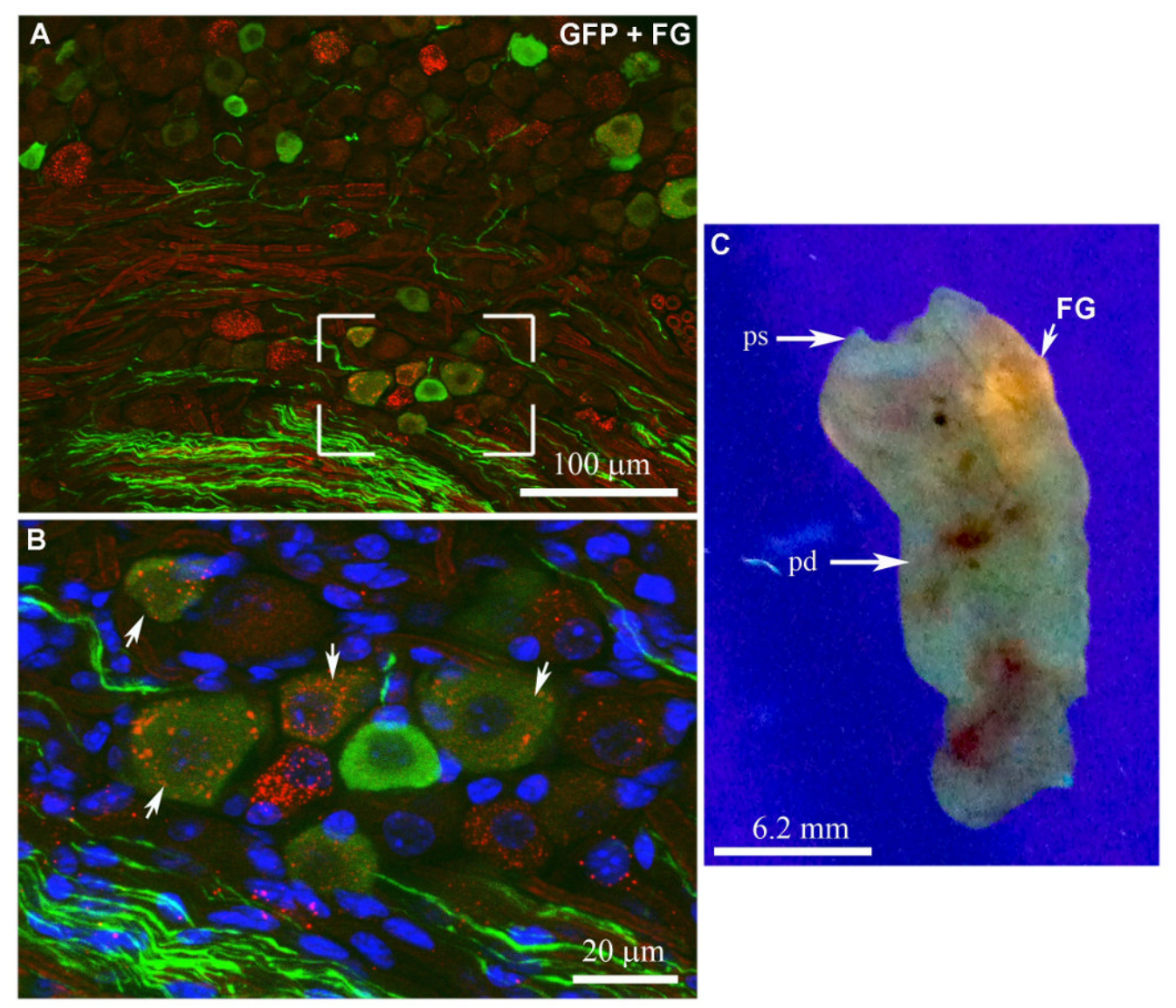

Figure 8.

Double immunolabeling for GFP and FG (A, B) in the nodose ganglion (epifluorescence and Apotome). The boxed area in $\mathrm{A}$ is magnified in $\mathrm{B}$. White arrows show examples of GFPpositive neurons (Alexa 488) also containing FG-positive vesicles (Alexa 594). Freshly isolated duodenum was flatten and exposed to ultraviolet light $(\mathrm{C})$. The white arrow shows one successful FG injection site. A magenta-green version is provided in supplementary figure 4. Abbreviations: FG, fluorogold; ps, pyloric sphincter; pd, proximal duodenum. 

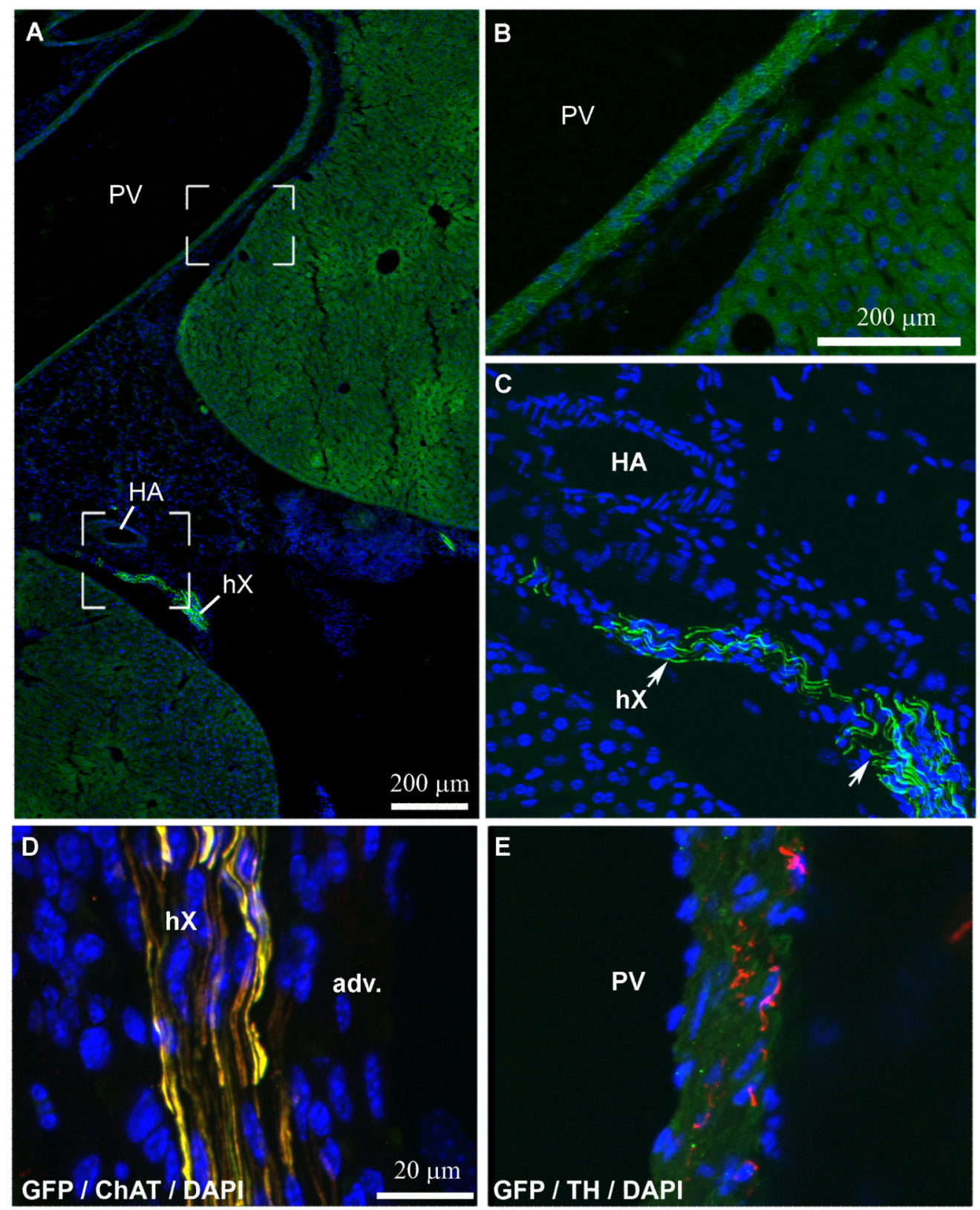

Figure 9.

Optical sections reconstruction (epifluorescence and Apotome) of GFP-positive fibers in the hepatic hilus (A-E). Sections are all counterstained with DAPI. Boxed areas in A are magnified in B and C. GFP-positive fibers are clearly seen traveling through the hepatic branch along the hepatic artery (C), but are absent in the portal vein and liver parenchyma (B). GFP-positive fibers running through the advential layers of the hepatic artery are all positive for ChAT (D). Of note, liver samples were collected to include the portal hilus as close as possible to the liver in order to obtain the hepatic proper division without the gastrointestinal division. TH immunoreactivity, but not GFP, is typically found in terminals wandering in the adventia of the portal vein (E). The white arrows show representative GFPpositive fibers. A magenta-green version is provided in supplementary figure 5. Scale bars in $\mathrm{B}$ and D apply to $\mathrm{C}$ and $\mathrm{E}$ respectively. Abbreviations: adv., advential layers; ChAT, choline 
acetyltransferase; HA, hepatic artery; $\mathrm{hX}$, hepatic branch of the vagus nerve, $\mathrm{PV}$, portal vein; TH, tyrosine hydroxylase. 


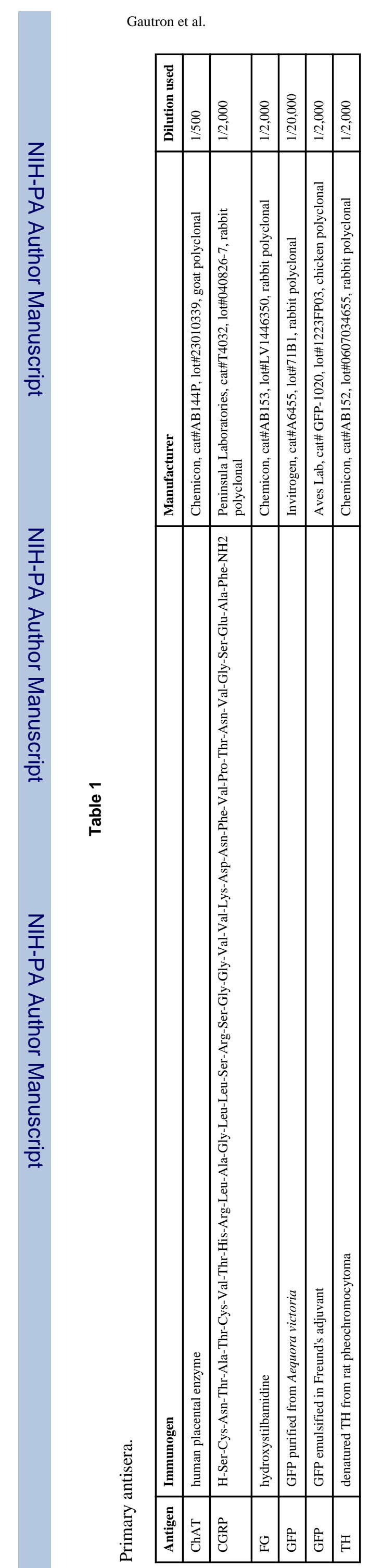

Page 25 
